\title{
Optimization of Antioxidant Potential of Penicillium granulatum Bainier by Statistical Approaches
}

\author{
Priyanka Chandra and Daljit Singh Arora \\ Microbial Technology Laboratory, Department of Microbiology, Guru Nanak Dev University, Amritsar 143005, India \\ Correspondence should be addressed to Daljit Singh Arora, daljit_02@yahoo.co.in
}

Received 15 February 2012; Accepted 13 March 2012

Academic Editors: M. Canica, J. Ruiz-Herrera, G. Suzzi, and T. P. West

Copyright ( $\odot 2012$ P. Chandra and D. S. Arora. This is an open access article distributed under the Creative Commons Attribution License, which permits unrestricted use, distribution, and reproduction in any medium, provided the original work is properly cited.

A three-step optimization strategy which includes one-factor-at-a-time classical method and different statistical approaches (Plackett-Burman design and response surface methodology) that were applied to optimize the antioxidant potential of Penicillium granulatum. Antioxidant activity was assayed by different procedures and compared with total phenolic content. Primarily, different carbon and nitrogen sources were screened by classical methods, which revealed sucrose and $\mathrm{NaNO}_{3}$ to be the most suitable. In second step, Plackett-Burman design also supported sucrose and $\mathrm{NaNO}_{3}$ to be the most significant. In third step, response surface analysis showed $4.5 \%$ sucrose, $0.1 \% \mathrm{NaNO}_{3}$, and incubation temperature of $25^{\circ} \mathrm{C}$ to be the optimal conditions. Under these conditions, the antioxidant potential assayed through different procedures was $78.2 \%, 70.1 \%$, and $78.9 \%$ scavenging effect for DPPH radical, ferrous ion, and nitric oxide ion, respectively. The reducing power showed an absorbance of 1.6 with $68.5 \%$ activity for FRAP assay.

\section{Introduction}

Antioxidants are the compounds that scavenge or neutralize free radicals. These are produced constantly in human body during normal physiological processes and are responsible for various pathological process like aging, cardiovascular diseases, diabetes, cancer, Alzheimer's disease, neurodegenerative disorders, atherosclerosis, cataracts, and inflammation [1].

Filamentous fungi are historically important sources of pharmacologically relevant secondary metabolites, and this group continues to provide new structures with novel biological activities [2]. The discovery of pharmaceutically significant novel product through screening of microbial secondary metabolites is an attraction in the pharmaceutical and biotechnological industry and is also becoming increasingly beneficial. There is widespread acceptance that fungi are virtually unlimited source of novel structures with many potential therapeutic applications including antibacterial, anticancer, anti-inflammatory, immunostimulatory, and antioxidant [3]. Recently, fungi have emerged as an important source of antioxidant compounds [4, 5]. Phenolic compounds are considered to be the main secondary metabolites in plants, mushrooms, and fungi responsible for their antioxidant activity [6-8].

Physiochemical and nutritional conditions greatly influence the growth as well as the activities of the microorganisms. Hence, optimization of such parameters is an important step for the enhancement of activity. Optimization is a tedious process due to involvement of multivariable parameters. The conventional one-factor-at-a-time approach of optimization is not only time consuming but often incapable of reaching the true optimum conditions. In the optimization process, screening of important factors is initially carried out, and these selected factors are then optimized by different techniques. The Plackett-Burman design is a wellknown and widely used statistical technique for screening and selection of most significant culture variables. Response surface methodology (RSM) is a three-factorial design that gives relationship between one or more measured dependent responses with a number of input (independent) factors. RSM has some advantages that include less experiment 
numbers, suitability for multiple factor experiments, search for relativity between factors, and finding of the most suitable conditions and forecast response [9]. In this paper, linear or quadratic effects of experimental variables help to construct contour plots and a model equation fitting the experimental data. This facilitates the determination of optimum value of factors under investigation and prediction of response under optimized condition [10].

The present study thus aims to optimize the conditions for enhancement of antioxidant activity of soil fungal isolate Penicillium granulatum Bainier by various assay procedures [1,1-diphenyl-2-picryl hydrazyl (DPPH) assay, reducing power, ferrous ion and nitric oxide ion scavenging activity, ferric reducing antioxidant power (FRAP) assay] using onefactor-at-a-time classical approach, Plackett-Burman design, and response surface methodology. An effort has been made to work out the correlation (if any) between antioxidant activity and total phenolic content.

\section{Materials and Methods}

2.1. Experimental. Penicillium granulatum Bainier was isolated from soil of Amritsar, Punjab, India ( $31^{\circ} 37^{\prime} 59^{\prime \prime}$ North, $74^{\circ} 51^{\prime} 56^{\prime \prime}$ East) and identified on the basis of standard protocol and the identity was confirmed by National Fungal Culture Collection of India, Agharkar Research Institute, Pune, India. To study the antioxidant potential, the fungus was grown on $50 \mathrm{~mL}$ Czapek Dox's broth (sucrose 3\%, $\mathrm{NaNO}_{3}$ 0.2\%, $\mathrm{K}_{2} \mathrm{HPO}_{4} 0.1 \%, \mathrm{MgSO}_{4} 0.05 \%, \mathrm{KCl} 0.05 \%$, $\mathrm{FeSO}_{4} 0.001 \%$ ). The medium was inoculated with two discs $(8 \mathrm{~mm})$ of fungal mycelia obtained from 6 to 7 days grown culture on Yeast extract glucose agar plates. The growth was carried out under stationary conditions at $25^{\circ} \mathrm{C}$. After incubation for 10 days, the culture broth was filtered through Whatmann filter paper no. 1, and the filtrate so obtained was analyzed for antioxidant potential by different assay procedures, and total phenolic content was estimated with Folin-Ciocalteau (FC) method.

2.2. Assay Procedures for Antioxidant Activity. Different assay procedures for antioxidant activity were used as described earlier [11]. The scavenging activity for DPPH free radicals was measured according to Zhao et al. [12] with slight modifications using $0.1 \mathrm{mM}$ DPPH solution in ethanol, and the decolourization of DPPH was determined by measuring the decrease in absorbance at $517 \mathrm{~nm}$, and the $\mathrm{DPPH}$ radical scavenging effect was calculated according to the following equation:

$$
\% \text { scavenging rate }=\left[1-\frac{(A 1-A 2)}{A 0}\right] \times 100,
$$

where $A 0$ represents the absorbance of the control (DPPH without extract), $A 1$ represents the absorbance of the reaction mixture, and $A 2$ represents the absorbance without DPPH (DPPH was replaced by same volume of distilled water).

The reducing power of the extracts was determined according to Chang et al. [13] using potassium ferricyanide, trichloroacetic acid, and $\mathrm{FeCl}_{3}$. Absorbance was read at $700 \mathrm{~nm}$ to determine the amount of ferric ferrocyanide (Prussian blue) formed. Higher absorbance of the reaction mixture indicates higher reducing power of the sample.

Ferric reducing antioxidant power (FRAP) assay was carried out according to Othman et al. [14] by monitoring the reduction of $\mathrm{Fe}^{3+}$-tripyridyl triazine (TPTZ) to blue colored $\mathrm{Fe}^{2+}$-TPTZ. The absorbance was measured at $593 \mathrm{~nm}$. Antioxidant potential of the sample was compared with the activity of $\mathrm{FeSO}_{4}$.

Ferrous ion scavenging (metal chelating) activity of the extracts was measured according to Zhao et al. [12] using $\mathrm{FeCl}_{2}$ and ferrozine and the absorbance measured at $562 \mathrm{~nm}$. The chelating activity was calculated as

$$
\text { Chelating rate }=\left[1-\frac{(A 1-A 2)}{A 0}\right] \times 10,
$$

where $A 0$ represents the absorbance of the control (without extract) $A 1$ represents the absorbance of reaction mixture, and $A 2$ represents the absorbance without $\mathrm{FeCl}_{2}$.

Nitric oxide production from sodium nitroprusside was measured according to $\mathrm{Ki}$ et al. [15] using sodium nitroprusside solution and Griess reagent. The absorbance was taken at $546 \mathrm{~nm}$ and compared with absorbance of $1 \mathrm{mg} / \mathrm{mL}$ of standard solution (sodium nitrite) treated in the same way with Griess reagent.

2.3. Determination of Total Phenolic Content (TPC). The total phenolic content was determined colorimetrically using the Folin-Ciocalteau (FC) method according to Singleton et al. [16] with some modifications [11], and the absorbance of the reaction mixture was measured at $765 \mathrm{~nm}$. Gallic acid was taken as standard.

2.4. Determination of Mycelial Biomass. The dry weight of mycelia was measured after repeated washing of the fungal biomass with distilled water and drying overnight at $70^{\circ} \mathrm{C}$ to a constant weight [17].

2.5. Medium Optimization Using One-Factor-at-a-Time Classical Method. To find out the best carbon source, sucrose in the Czapek Dox's medium was replaced with same concentration of one of the sugars (glucose, maltose, lactose, and starch, and glycerol) and to work out the best nitrogen source, $\mathrm{NaNO}_{3}$ in Czapek Dox's medium was substituted with one or the other inorganic nitrogen source $\left(\mathrm{KNO}_{3}, \mathrm{NH}_{4} \mathrm{NO}_{3},\left(\mathrm{NH}_{4}\right)_{2} \mathrm{Cl},\left(\mathrm{NH}_{4}\right)_{2} \mathrm{SO}_{4},\left(\mathrm{NH}_{4}\right) \mathrm{H}_{2} \mathrm{SO}_{4}\right)$ or nitrogen-rich organic supplement (yeast extract, peptone, malt extract, urea, casein, soyabean meal).

\subsection{Statistical Optimization of the Medium}

2.6.1. Plackett-Burman Experimental Design. The PlackettBurman experimental design is a valuable tool for the rapid evaluation of the effects of various medium components. Because this design is a preliminary optimization technique, which tests only two levels of each medium component, it cannot provide the optimal quantity of each component 
required in the medium. This technique, however, provides indications of how each component tends to affect the activity. The screening of most significant parameters affecting antioxidant potential was studied by the PlackettBurman design. The 5 factors, which are components of Czapek Dox's medium (sucrose, $\mathrm{NaNO}_{3}, \mathrm{~K}_{2} \mathrm{HPO}_{4}, \mathrm{KCl}$, and $\mathrm{MgSO}_{4}$ ), were examined. Total 14 tests were designed including 12 combinations and 2 repetitions at central point which contain different concentration of each factor, and the effect of each factor was determined by the difference between the average of the + and - responses. The significance level of effect of each factor was determined by student's $t$ test.The most common mean of assessing significant value is the $P$ value which was also evaluated for each factor.

2.6.2. Response Surface Methodology through Box-Behnken Designs. On the basis of results from screening of different carbon and nitrogen sources through one-factor-at-a-time classical method and different components by PlackettBurman design, sucrose and $\mathrm{NaNO}_{3}$ were found to be the best for antioxidant activity. Sucrose as carbon source, $\mathrm{NaNO}_{3}$ as nitrogen source and temperature were taken independent variables for the optimization by RSM using Box-Behnken designs of experiments. Each variable was studied at three levels $(-1,0,+1)$; for sucrose these were $5 \%$, $3 \%$, and $1 \% ; \mathrm{NaNO}_{3}: 0.05 \%, 0.2 \%$, and $0.35 \%$; temperature: $15^{\circ} \mathrm{C}, 25^{\circ} \mathrm{C}$, and $35^{\circ} \mathrm{C}$.

The experimental design included 17 flasks with five replicates having all the three variables at their central coded values. The DPPH assay, reducing power, ferrous ion, and nitric oxide ion scavenging activity, FRAP assay, and their total phenolic contents were taken as responses $G_{(1-6)}$. The mathematical relationship of response $G$ (for each parameter) and independent variable $X\left(X_{1}\right.$, sucrose; $X_{2}$, $\mathrm{NaNO}_{3} ; X_{3}$, temperature) was calculated by the following quadratic model equation:

$$
\begin{aligned}
G_{(1-6)}= & \beta_{0}+\beta_{1} X_{1}+\beta_{2} X_{2}+\beta_{3} X_{3} \\
& +\beta_{11} X^{2}{ }_{1}+\beta_{22} X^{2}{ }_{2}+\beta_{33} X^{2}{ }_{3} \\
& +\beta_{12} X_{1} X_{2}+\beta_{13} X_{1} X_{3}+\beta_{23} X_{2} X_{3},
\end{aligned}
$$

where $G$ is the predicted response; $\beta_{0}$, intercept; $\beta_{1}, \beta_{2}$, and $\beta_{3}$, linear coefficients; $\beta_{11}, \beta_{22}$ and $\beta_{33}$, squared coefficients $\beta_{12}, \beta_{13}$, and $\beta_{23}$ interaction coefficients. MINITAB version 11 statistical software was used to obtain optimal working conditions and generate response surface graphs. Statistical analysis of experimental data was also performed using this software.

2.7. Toxicity Tests. The culture broth used to assess the antioxidant activity was subject to Ames test by using Salmonella reverse mutation based on histidine dependence and mutations in S. typhimurium [18]. Cytotoxicity was tested by using 3-(4,5-dimethylthiazol-2-yl)-2,5-diphenyl tetrazolium bromide (MTT) method. The fungal extracts $(100 \mu \mathrm{l})$ were incubated with $1 \times 10^{5} \mathrm{RBCs} /$ well in 96-well
ELISA plates for $24 \mathrm{~h}$. Then $100 \mu \mathrm{l}$ MTT solution $(0.5 \%$, w $/ \mathrm{v})$ was added to each well and incubated further for $4 \mathrm{~h}$. After incubation, the supernatant was removed, and $100 \mu \mathrm{l}$ DMSO was added to each well to dissolve the formazan crystals. The absorbance was measured at $590 \mathrm{~nm}$ using an automated microplate reader. The wells with untreated cells served as control [19].

\section{Results and Discussion}

Fungi are recognized as prolific secondary metabolite producers and have provided several bioactive compounds and chemical models, currently used as pharmaceuticals. Recently, they have attracted the attention of scientific community to produce wide range of secondary metabolites possessing antioxidant activity along with their amenability to easy manipulations. Nutritional and fermentation conditions have a great influence on secondary metabolites production. Optimization of fermentation medium and conditions is very important for maximizing the yield and minimizing the production cost of many secondary metabolites. Most of the recent optimization efforts have relied on statistical experimental design and response surface analyses [20]. Thus, the present study is based on statistical design as it is a powerful tool that can be used to account for the main as well as interactive influences of fermentation parameters on the process performance. It is an efficient way to generate useful information with limited experimentation, thereby cutting the process development time and cost [21].

Effects of different carbon and nitrogen sources on antioxidant potential were studied by various assay procedures. Initially, to assess the antioxidant potential by various assay procedures all the experimentation was done by growing Penicillium granulatum on Czapek Dox's broth medium. Carbohydrates are the structural and storage compounds in the cells of fungi and thereby play a key role in the growth as well as in the production of various useful secondary metabolites. Of the various carbon sources tested, sucrose supported the maximum antioxidant activity by Penicillium granulatum which is in consonance with earlier studies carried out on Aspergillus candidus [22]. Though, it contravenes the general perception that glucose and starch are known to be the best carbon source for the fungal growth. The order for different carbon sources supportive of best antioxidant activity was found to be sucrose > dextrose $>$ maltose $>$ lactose $>$ starch $>$ glycerol (Table 1 ). Sucrose was thus selected as the carbon source for further experimentation, which was also found to be the best during earlier studies on Aspergillus spp. [11].

Similarly, $\mathrm{NaNO}_{3}$ turned out to be the best nitrogen source to support maximum antioxidant potential. Peptone and yeast extract were other nitrogen-rich sources while urea gave the poorest activity. $\mathrm{NO}$ ion scavenging activity was monitored for $180 \mathrm{~min}$ (data not shown) which increased gradually with respect to time, however, data recorded at $180 \mathrm{~min}$ is only shown (Table 2). The antioxidant profile of Penicillium granulatum for different carbon and nitrogen sources remained the same irrespective of assay procedures 
TABLE 1: Effect of various carbon sources on antioxidant potential of Penicillium granulatum.

\begin{tabular}{|c|c|c|c|c|c|c|}
\hline$\%$ activity & Dextrose & Maltose & Lactose & Starch & Glycerol & Sucrose \\
\hline $\mathrm{DPPH}^{\mathrm{a}}$ assay & $72 \pm 0.2$ & $62.8 \pm 0.11$ & $64.3 \pm 0.1$ & $60.2 \pm 0.1$ & $50.2 \pm 0.9$ & $72.4 \pm 0.21$ \\
\hline Reducing power & $0.90 \pm 0.8$ & $0.53 \pm 0.8$ & $0.686 \pm 0.2$ & $0.52 \pm 0.02$ & $0.32 \pm 0.08$ & $0.980 \pm 0.18$ \\
\hline $\mathrm{Fe}^{2+}$ scavenging activity & $64.8 \pm 0.3$ & $54.3 \pm 0.2$ & $45.2 \pm 0.32$ & $40.3 \pm 0.2$ & $42.4 \pm 0.5$ & $64.2 \pm 0.17$ \\
\hline FRAP $^{\mathrm{b}}$ assay & $60.2 \pm 0.21$ & $50.8 \pm 0.3$ & $40.3 \pm 0.35$ & $38.2 \pm 0.5$ & $40.2 \pm 0.2$ & $61.9 \pm 0.04$ \\
\hline \multicolumn{7}{|l|}{$\mathrm{NO}^{c}$ scavenging activity } \\
\hline $30 \mathrm{~min}$ & $46.2 \pm 0.03$ & $20.8 \pm 0.01$ & $20.1 \pm 0.2$ & $22.1 \pm 0.02$ & $22.7 \pm 0.2$ & $35.01 \pm 0.01$ \\
\hline $60 \mathrm{~min}$ & $48.0 \pm 0.1$ & $37.3 \pm 0.1$ & $24.2 \pm 0.1$ & $24.2 \pm 0.31$ & $25.1 \pm 0.05$ & $42.8 \pm 0.01$ \\
\hline $90 \mathrm{~min}$ & $51.4 \pm 0.9$ & $41.2 \pm 0.5$ & $36.7 \pm 0.011$ & $29.3 \pm 0.011$ & $28.9 \pm 0.1$ & $53.16 \pm 0.16$ \\
\hline $120 \mathrm{~min}$ & $60.3 \pm 0.1$ & $48.2 \pm 0.06$ & $38.4 \pm 0.01$ & $37.4 \pm 0.71$ & $30.5 \pm 0.2$ & $62.98 \pm 0.04$ \\
\hline $180 \mathrm{~min}$ & $65.2 \pm 0.1$ & $52.3 \pm 0.5$ & $42.3 \pm 0.9$ & $40.7 \pm 0.8$ & $38.5 \pm 0.05$ & $68.2 \pm 0.21$ \\
\hline $\mathrm{TPC}^{\mathrm{d}}(\mathrm{mg} / \mathrm{mL})$ & $7.1 \pm 0.03$ & $4.0 \pm 0.1$ & $4.3 \pm 0.02$ & $3.4 \pm 0.02$ & $2.2 \pm 0.06$ & $7.28 \pm 0.02$ \\
\hline Biomass (g/L) & $4.5 \pm 0.005$ & $2.3 \pm 0.045$ & $2.01 \pm 0.076$ & $4.08 \pm 0.09$ & $1.50 \pm 0.02$ & $3.05 \pm 0.005$ \\
\hline
\end{tabular}

${ }^{\mathrm{a}}$ DPPH-1.1-diphenyl-2-picryl hydrazyl; ${ }^{\mathrm{b}}$ FRAP- ferric reducing antioxidant power; ${ }^{\mathrm{c}} \mathrm{NO}$-nitric oxide; ${ }^{\mathrm{d}}$ TPC-total phenolic content.

TABLE 2: Effect of various nitrogen sources on antioxidant potential of Penicillium granulatum.

\begin{tabular}{|c|c|c|c|c|c|c|c|}
\hline Nitrogen sources & $\begin{array}{l}\mathrm{DPPH}^{\mathrm{a}} \\
\text { assay }\end{array}$ & Reducing power & $\begin{array}{c}\mathrm{Fe}^{2+} \text { scavenging } \\
\text { activity }\end{array}$ & FRAP $^{\mathrm{b}}$ assay & $\begin{array}{c}\mathrm{NO}^{c} \text { scavenging } \\
\text { activity }\end{array}$ & $\begin{array}{c}\mathrm{TPC}^{\mathrm{d}} \\
(\mathrm{mg} / \mathrm{mL})\end{array}$ & $\begin{array}{l}\text { Biomass } \\
(\mathrm{g} / \mathrm{L})\end{array}$ \\
\hline \multicolumn{8}{|c|}{$\begin{array}{l}\text { Nitrogen rich organic } \\
\text { supplements }\end{array}$} \\
\hline Yeast extract & $72.0 \pm 0.12$ & $0.9 \pm 0.8$ & $63.2 \pm 0.02$ & $60.2 \pm 0.1$ & $65.8 \pm 0.21$ & $7.3 \pm 0.33$ & $4.2 \pm 0.08$ \\
\hline Peptone & $71.2 \pm 0.3$ & $0.93 \pm 0.6$ & $60.8 \pm 0.52$ & $59.8 \pm 0.2$ & $63.2 \pm 0.5$ & $6.9 \pm 0.1$ & $4.25 \pm 0.05$ \\
\hline Malt extract & $62.6 \pm 0.1$ & $0.62 \pm 0.02$ & $50.2 \pm 0.2$ & $48.2 \pm 0.6$ & $45.4 \pm 0.91$ & $4.0 \pm 0.12$ & $3.0 \pm 0.08$ \\
\hline Casein & $60.8 \pm 0.2$ & $0.374 \pm 0.23$ & $32.7 \pm 0.3$ & $30.2 \pm 0.3$ & $27.3 \pm 0.1$ & $3.1 \pm 0.42$ & $3.0 \pm 0.002$ \\
\hline Soyabean meal & $68.2 \pm 0.56$ & $0.63 \pm 0.1$ & $60.2 \pm 0.56$ & $55.8 \pm 0.67$ & $56.3 \pm 0.54$ & $4.1 \pm 0.21$ & $2.45 \pm 0.08$ \\
\hline Urea & $30.8 \pm 0.4$ & $0.103 \pm 0.21$ & $22.3 \pm 0.34$ & $20.8 \pm 0.78$ & - & $1.2 \pm 0.34$ & $0.9 \pm 0.06$ \\
\hline \multicolumn{8}{|c|}{ Inorganic nitrogen sources } \\
\hline $\mathrm{KNO}_{3}$ & $60.3 \pm 0.3$ & $0.50 \pm 0.45$ & $56.3 \pm 0.56$ & $54.2 \pm 0.98$ & $50.2 \pm 0.32$ & $3.4 \pm 0.21$ & $2.3 \pm 0.07$ \\
\hline$\left(\mathrm{NH}_{4}\right)_{2} \mathrm{SO}_{4}$ & $53.8 \pm 0.56$ & $0.29 \pm 0.6$ & $50.6 \pm 0.78$ & $49.7 \pm 0.21$ & $48.8 \pm 0.5$ & $2.8 \pm 0.03$ & $2.25 \pm 0.07$ \\
\hline$\left(\mathrm{NH}_{4}\right) \mathrm{H}_{2} \mathrm{SO}_{4}$ & $50.6 \pm 0.2$ & $0.22 \pm 0.8$ & $42.8 \pm 0.89$ & $40.6 \pm 0.3$ & $36.7 \pm 0.8$ & $2.1 \pm 0.04$ & $2.3 \pm 0.03$ \\
\hline $\mathrm{NH}_{4} \mathrm{NO}_{3}$ & $55.4 \pm 0.6$ & $0.31 \pm 0.98$ & $53.2 \pm 0.34$ & $51.2 \pm 0.9$ & $50.2 \pm 0.5$ & $3.1 \pm 0.7$ & $2.3 \pm 0.06$ \\
\hline $\mathrm{NaNO}_{3}$ & $72.4 \pm 0.21$ & $0.98 \pm 0.18$ & $64.2 \pm 0.17$ & $61.9 \pm 0.04$ & $68.2 \pm 0.21$ & $7.28 \pm 0.02$ & $3.0 \pm 0.005$ \\
\hline$\left(\mathrm{NH}_{4}\right)_{2} \mathrm{Cl}$ & $60.2 \pm 0.2$ & $0.47 \pm 0.24$ & $54.8 \pm 0.23$ & $52.8 \pm 0.5$ & $50.6 \pm 0.4$ & $3.2 \pm 0.5$ & $2.45 \pm 0.07$ \\
\hline
\end{tabular}

${ }^{\mathrm{a}}$ DPPH-1.1-diphenyl-2-picryl hydrazyl; ${ }^{\mathrm{b}}$ FRAP- ferric reducing antioxidant power; ${ }^{\mathrm{c}} \mathrm{NO}$-nitric oxide; ${ }^{\mathrm{d}}$ TPC-total phenolic content.

adopted, which also shows the ability of extract to scavenge different types of free radicals.

The above results thus explain that a fungal species may have the ability to utilize a particular carbon source for vegetative growth but may not be able to use it for production of specialized structural molecules. Sucrose and $\mathrm{NaNO}_{3}$ are regarded as sustainable sources, which favors the production of secondary metabolites [23]. The study thus demonstrated the basic composition of Czapek Dox's medium to be the best for effective antioxidant activity in consonance with earlier studies [11]. In fact, the designing of culture media has a major impact on the growth of microbes and the production of microbial products [24].

Biomass did not significantly affect the activity, as dextrose-supported maximum biomass followed by starch but maximum antioxidant potential, as assayed by different procedures, was demonstrated by sucrose. Similarly, yeast extract followed by peptone supported maximum biomass but sodium nitrate showed highest activity. However, urea gave minimum biomass accompanied by minimum activity. These observations are in agreement with earlier study on Lentinula edodes which also did not show any correlation between mycelial biomass and antibacterial activity [25].

The total phenolic content (TPC) of Penicillium granulatum extracts has been expressed as gallic acid equivalent (GAE), that is, mg gallic acid/100 mL culture. TPC is known to be responsible for antioxidant activity, and the Penicillium granulatum possessed high TPC, which is positively correlated with its antioxidant potential. The highest TPC yield was $7.28 \mathrm{mg} / \mathrm{mL}$ in the presence of sucrose and $\mathrm{NaNO}_{3}$ in the medium. On the basis of above results, Czapek Dox's broth medium was chosen for remaining experimentations. It is 
TABLE 3: Plackett-Burman design variables with different antioxidant potential as response.

\begin{tabular}{|c|c|c|c|c|c|c|c|c|c|c|c|}
\hline \multirow[b]{2}{*}{ Run } & \multicolumn{5}{|c|}{ Variables (\%) } & \multicolumn{6}{|c|}{ Antioxidant activity (\% activity) } \\
\hline & Sucrose & $\mathrm{NaNO}_{3}$ & $\mathrm{~K}_{2} \mathrm{HPO}_{4}$ & $\mathrm{MgSO}_{4}$ & $\mathrm{KCl}$ & $\begin{array}{l}\text { DPPH } \\
\text { Assay }\end{array}$ & $\begin{array}{l}\text { Reducing } \\
\text { power }\end{array}$ & $\begin{array}{c}\mathrm{Fe}^{2+} \text { scavenging } \\
\text { activity }\end{array}$ & FRAP assay & $\begin{array}{c}\text { NO } \\
\text { scavenging } \\
\text { activity }\end{array}$ & $\begin{array}{c}\text { TPC } \\
(\mathrm{mg} / \mathrm{mL})\end{array}$ \\
\hline 1 & 5.0 & 0.000 & 0.18 & 0.000 & 0.000 & 60.8 & 0.63 & 50.8 & 46.7 & 52.7 & 4.1 \\
\hline 2 & 5.0 & 0.350 & 0.00 & 0.090 & 0.000 & 70.5 & 0.73 & 60.9 & 58.6 & 63.8 & 5.1 \\
\hline 3 & 0.0 & 0.350 & 0.18 & 0.000 & 0.090 & 22.5 & 0.22 & 15.5 & 13.2 & 16.7 & 1.2 \\
\hline 4 & 5.0 & 0.000 & 0.18 & 0.090 & 0.000 & 50.7 & 0.58 & 40.9 & 40.8 & 45.3 & 3.2 \\
\hline 5 & 5.0 & 0.350 & 0.00 & 0.090 & 0.090 & 72.8 & 0.96 & 63.8 & 60.5 & 66.8 & 6.2 \\
\hline 6 & 5.0 & 0.350 & 0.18 & 0.000 & 0.090 & 64.5 & 0.68 & 55.7 & 52.8 & 60.9 & 5.8 \\
\hline 7 & 0.0 & 0.350 & 0.18 & 0.090 & 0.000 & 18.6 & 0.18 & 10.9 & 8.9 & 12.4 & 0.8 \\
\hline 8 & 0.0 & 0.000 & 0.18 & 0.090 & 0.090 & 44.8 & 0.50 & 36.7 & 36.5 & 40.7 & 2.8 \\
\hline 9 & 0.0 & 0.000 & 0.00 & 0.090 & 0.090 & 20.7 & 0.18 & 15.5 & 12.2 & 14.6 & 0.9 \\
\hline 10 & 5.0 & 0.000 & 0.00 & 0.000 & 0.090 & 61.8 & 0.65 & 50.6 & 48.6 & 55.8 & 4.8 \\
\hline 11 & 0.0 & 0.350 & 0.00 & 0.000 & 0.000 & 54.3 & 0.59 & 44.1 & 42.7 & 48.6 & 3.2 \\
\hline 12 & 0.0 & 0.000 & 0.00 & 0.000 & 0.000 & 0.0 & 0.00 & 0.0 & 0.0 & 0.0 & 0.0 \\
\hline 13 & 2.5 & 0.175 & 0.09 & 0.045 & 0.045 & 73.2 & 0.98 & 65.7 & 62.9 & 69.3 & 7.9 \\
\hline 14 & 2.5 & 0.175 & 0.09 & 0.045 & 0.045 & 72.8 & 0.98 & 64.6 & 62.8 & 68.7 & 7.8 \\
\hline
\end{tabular}

commonly known that the antioxidative effects are mainly due to redox properties of phenolic compounds which can play an important role in absorbing and neutralizing free radicals by acting as reducing agents and hydrogen donor or quenching singlet and triplet oxygen or decomposing peroxides [4]. The importance of phenolic contents has been endorsed by their high content in Penicillium granulatum, and their antioxidant activity is quite comparable to that of many mushrooms as well as medicinal plants.

3.1. Plackett-Burman Design for Selection of Significant Components. A Plackett-Burman design experiment was employed to evaluate the influence of five factors (sucrose, $\mathrm{NaNO}_{3}, \mathrm{~K}_{2} \mathrm{HPO}_{4}, \mathrm{KCl}$, and $\mathrm{MgSO}_{4}$ ) and their importance in culture medium to obtain better antioxidant activity. Antioxidant potential of Penicillium granulatum assayed by different procedures and extracellularly produced total phenolic content varied significantly with the 14 run of different combinations of the media components (Table 3 ). The maximum antioxidant potential along with high TPC was observed in run order 13 and run order 14 which was followed by run order 5 . The results were subjected to regression analysis and the analysis of variance (ANOVA) which revealed sucrose and $\mathrm{NaNO}_{3}$ to have statistically significant effect on antioxidant potential with $P$ value $\leq 0.05$ and $\leq 0.5$, respectively which showed that of the five variables only sucrose and $\mathrm{NaNO}_{3}$ played a critical role for antioxidant activity. Based on these results, sucrose and $\mathrm{NaNO}_{3}$ were selected as two variables and applied to optimize the medium composition by RSM. To know the optimum temperature and its interaction with other variables (sucrose and $\mathrm{NaNO}_{3}$ ), it was chosen as a third variable as it is the important physical parameter that affects the activity as well as fungal growth.

\subsection{Box-Behnken Design}

3.2.1. Fitting the Model. The data obtained from quadratic model equation was found to be significant. It was verified by $F$ value and the analysis of variance (ANOVA) by fitting the data of all independent observations in response surface quadratic model (Table 4 ). $R^{2}$ value for all the responses ranged between 86 and $95 \%$ which showed suitable fitting of the model in the designed experiments (Table 5). The final predictive equations for each response: DPPH assay $\left(G_{1}\right)$, reducing power $\left(G_{2}\right)$, ferrous ion scavenging activity $\left(G_{3}\right)$, FRAP assay $\left(G_{4}\right)$ and nitric oxide ion scavenging activity $\left(G_{5}\right)$, and their total phenolic contents $\left(G_{6}\right)$ obtained are as follow:

$$
\begin{aligned}
G_{(1)}= & -13.71+24.75 X_{1}+142.02 X_{2} \\
& +2.00 X_{3}-2.74 X^{2}{ }_{1}+19.62 X^{2}{ }_{2} \\
& -0.03 X^{2}{ }_{3}-47.50 X_{1} X_{2} \\
& +0.07 X_{1} X_{3}-0.49 X_{2} X_{3}, \\
G_{(2)}= & -1.483+0.504 X_{1}+3.966 X_{2} \\
& +0.080 X_{3}-0.050 X^{2}{ }_{1}+0.989 X^{2}{ }_{2} \\
& --0.001 X^{2}{ }_{3}-1.450 X_{1} X_{2} \\
& +0.005 X_{1} X_{3}-0.010 X_{2} X_{3}, \\
G_{(3)}= & -7.73+21.60 X_{1}+104.91 X_{2} \\
& +1.75 X_{3}--2.45 X^{2}{ }_{1}+46.89 X^{2}{ }_{2} \\
& -0.02 X^{2}{ }_{3}-38.58 X_{1} X_{2}+0.04 X_{1} X_{3} \\
& -0.60 X_{2} X_{3},
\end{aligned}
$$




$$
\begin{aligned}
G_{(4)}= & -1.38+18.06 X_{1}+101.89 X_{2} \\
& +1.51 X_{3}-1.92 X^{2}{ }_{1}-8.89 X^{2}{ }_{2}-0.02 X^{2}{ }_{3} \\
& -38.17 X_{1} X_{2}+0.05 X_{1} X_{3}+0.15 X_{2} X_{3}, \\
G_{(5)}= & -1.57+21.30 X_{1}+114.35 X_{2} \\
& +1.48 X_{3}-2.57 X^{2}{ }_{1}+110.38 X^{2}{ }_{2} \\
& -0.02 X^{2}{ }_{3}-40.92 X_{1} X_{2}+0.11 X_{1} X_{3} \\
& -1.67 X_{2} X_{3}, \\
G_{(6)}= & -21.30+6.87 X_{1}+40.84 X_{2} \\
& +1.00 X_{3}-0.64 X_{1}^{2}+21.22 X_{2}^{2} \\
& -0.01 X^{2}{ }_{3}-11.50 X_{1} X_{2} \\
& -0.02 X_{1} X_{3}-0.92 X_{2} X_{3} .
\end{aligned}
$$

The optimized values of factors were validated by repeating the experiment in triplicate flasks.

3.2.2. Effect of Different Variables on DPPH Assay. Sucrose significantly affected the DPPH activity. The linear effect $\left(X_{1}\right)$, squared effect $\left(X_{1}^{2}\right)$ as well as interactive effect $\left(X_{1} X_{2}\right)$ were highly significant $(P$ value $<0.005)$. Linear effect $\left(X_{2}\right)$ was significant with $P$ value $<0.5$. The response surface graphs showed the highest activity at concentration of sucrose between 3 and 5\% but with least amount of $\mathrm{NaNO}_{3}$. Maximum predicted value for DPPH scavenging effect $(80 \%)$ was obtained at $4.5 \%$ of sucrose, $0.05 \%$ of $\mathrm{NaNO}_{3}$ and at $25^{\circ} \mathrm{C}$ (Figure $1(\mathrm{a})$ ).

3.2.3. Effect of Variables on Reducing Power. Linear effects $\left(X_{1}, X_{2}, X_{3}\right)$ and squared effects $\left(X_{1}^{2}\right)$ were significant with $P$ value $<0.5$. Interactive effect $\left(X_{1} X_{2}\right)$ was most significant at $P$ value $\leq 0.005$. The response surface graphs showed the highest reducing potential with an absorbance of 1.6 , when the concentration of sucrose is $4.5 \%$ with $0.05 \%$ of $\mathrm{NaNO}_{3}$ and at a temperature of $35^{\circ} \mathrm{C}$ (Figure 1(b)).

3.2.4. Effect of Variables on FRAP Assay, Ferrous Ion, and Nitric Oxide Ion Scavenging Activity. For FRAP assay, interactive effect $\left(X_{1} X_{2}\right)$, linear $\left(X_{1}\right)$, and its squared effect $\left(X_{3}{ }^{2}\right)$ showed significance at $P \leq 0.05$. Interactive effect $\left(X_{1} X_{2}\right)$ was significant with $P$ value $\leq 0.005$, while linear effect $\left(X_{1}, X_{2}\right)$ showed significance at $P \leq 0.05$ for ferrous ion scavenging activity. Linear effect $\left(X_{1}, X_{2}\right)$ was significant with $P$ value $\leq$ 0.005 and interactive effect $\left(X_{1} X_{2}\right)$ showed significance at $P \leq 0.05$ for nitric oxide ion scavenging activity. Ferric reducing antioxidant power was maximum (70\%) at $30^{\circ} \mathrm{C}$, with medium composition of $4 \%$ of sucrose with $0.05 \%$ of $\mathrm{NaNO}_{3}$ (Figure 1(c)). Similarly, highest scavenging effect of $85 \%$ for nitric oxide ion was observed at $35^{\circ} \mathrm{C}$ with $4.5 \%$ and $0.05 \%$ of sucrose and $\mathrm{NaNO}_{3}$ respectively (Figure $1(\mathrm{~d}))$. The chelating effect was highest $(70 \%)$ at $25^{\circ} \mathrm{C}$ in the medium containing $4 \%$ of sucrose with $0.05 \%$ of $\mathrm{NaNO}_{3}$ (Figure 1(e)). Antioxidant potential as assayed by different procedures demonstrated decrease in activity with the further increase of $\mathrm{NaNO}_{3}$ concentration and decrease in the temperature and sucrose concentration.

3.2.5. Effect of Variables on Total Phenolic Content. The interactive effect $\left(X_{1} X_{2}\right)$ was highly significant with $P$ value $\leq 0.005$ while linear $\left(X_{1}\right)$ and squared effect of sucrose $\left(X_{1}^{2}\right)$ and interactive between sucrose-temperature $\left(X_{1} X_{3}\right)$ is significant with $P$ value $\leq 0.05$. The highest amount of TPC was obtained at $4 \%$ of sucrose and with $0.05 \%$ of $\mathrm{NaNO}_{3}$ concentration at $25^{\circ} \mathrm{C}$ (Figure $1(\mathrm{f})$ ) and yield decreased with the decrease in temperature and sucrose concentration and with the increase in $\mathrm{NaNO}_{3}$ concentration.

3.2.6. Validation of Results. On the basis of the results, sucrose and $\mathrm{NaNO}_{3}$ were found to be significant, thus, endorsing the important role played by carbon and nitrogen source to regulate secondary metabolite production and the microbial growth [26].

Though $\mathrm{KCl}, \mathrm{MgSO}_{4}$ and $\mathrm{K}_{2} \mathrm{HPO}_{4}$ did not significantly affect the antioxidant activity but are retained at standard concentration in Czapek Dox's medium because magnesium and potassium are required by all the fungi for a variety of regulatory functions and control the biosynthesis of various secondary metabolites. This shows that the medium most suitable for growth may or may not be equally effective for secondary metabolites, and thus enhancement of secondary metabolites can only be achieved through systematic manipulation of different parameters [27].

Thus, from the overall assessment, the optimized conditions for different assay procedures may be concluded as, $4.5 \%$ sucrose, $0.05 \% \mathrm{NaNO}_{3}$, and incubation temperature of $25^{\circ} \mathrm{C}$ while other media components were retained as standard concentration in Czapek Dox's medium. The $F$ value and $R^{2}$ value showed that the model correlated well with measured data and was statistically significant. To confirm the model adequacy for predicting maximum scavenging activity, the verification experiment using the optimum medium composition (mentioned above) was performed. The experiments under optimized conditions were carried out in triplicates which showed 78.2\%, 70.1\% and $78.9 \%$ scavenging effect for DPPH radical, ferrous ion, and nitric oxide ion, respectively. The yield for TPC was $12.3 \mathrm{mg} / \mathrm{mL}$, and reducing potential showed an absorbance of 1.6 with $68.5 \%$ activity for FRAP assay. The results showed the scavenging effect for DPPH radical, ferrous ion and nitric oxide ion was enhanced by 1.0, 1.0, and 1.15 folds, respectively while reducing potential and ferric reduction rate was enhanced by 1.7 and 1.1 folds. The production of TPC was enhanced by 1.7 folds. A good agreement between the predicted and experimental results verified the validity of the model and the improvement of antioxidant activity indicated that RSM is a powerful tool for determining the exact optimal values of the individual factors and the maximum response value. 
TABLE 4: Box-Behnken designs of different variables with their responses.

\begin{tabular}{|c|c|c|c|c|c|c|c|c|c|}
\hline \multicolumn{4}{|c|}{ Variables (\%) } & \multicolumn{6}{|c|}{ Antioxidant activity (\% activity) } \\
\hline Run & Sucrose & $\mathrm{NaNO}_{3}$ & Temperature & $\begin{array}{c}\text { DPPH } \\
\text { assay }\end{array}$ & $\begin{array}{c}\text { Reducing } \\
\text { power }\end{array}$ & $\begin{array}{c}\mathrm{Fe}^{2+} \text { scavenging } \\
\text { activity }\end{array}$ & $\begin{array}{l}\text { FRAP } \\
\text { assay }\end{array}$ & $\begin{array}{c}\text { NO scavenging } \\
\text { activity }\end{array}$ & $\begin{array}{c}\mathrm{TPC} \\
(\mathrm{mg} / \mathrm{mL})\end{array}$ \\
\hline 1 & 1 & 0.05 & 25 & 50.20 & 0.540 & 48.3 & 46.1 & 52.90 & 3.1 \\
\hline 2 & 5 & 0.05 & 25 & 77.40 & 1.320 & 68.9 & 66.9 & 74.80 & 12.6 \\
\hline 3 & 1 & 0.35 & 25 & 76.20 & 1.260 & 66.6 & 65.2 & 72.90 & 6.4 \\
\hline 4 & 5 & 0.35 & 25 & 46.40 & 0.300 & 40.9 & 40.2 & 45.70 & 2.1 \\
\hline 5 & 1 & 0.2 & 15 & 45.50 & 0.345 & 40.7 & 41.9 & 44.80 & 2.2 \\
\hline 6 & 5 & 0.2 & 15 & 48.10 & 0.460 & 42.3 & 43.2 & 47.60 & 2.8 \\
\hline 7 & 1 & 0.2 & 35 & 68.30 & 0.770 & 62.3 & 60.4 & 62.80 & 6.9 \\
\hline 8 & 5 & 0.2 & 35 & 76.20 & 1.250 & 66.8 & 65.8 & 74.80 & 6.1 \\
\hline 9 & 3 & 0.05 & 15 & 66.90 & 0.650 & 60.5 & 58.6 & 64.60 & 4.2 \\
\hline 10 & 3 & 0.35 & 15 & 67.90 & 0.689 & 62.9 & 54.5 & 70.60 & 5.7 \\
\hline 11 & 3 & 0.05 & 35 & 75.40 & 1.200 & 66.7 & 65.7 & 74.90 & 12.1 \\
\hline 12 & 3 & 0.35 & 35 & 73.44 & 1.180 & 65.5 & 62.5 & 70.90 & 8.1 \\
\hline 13 & 3 & 0.2 & 25 & 72.70 & 0.980 & 64.2 & 61.8 & 68.90 & 7.4 \\
\hline 14 & 3 & 0.2 & 25 & 73.80 & 1.020 & 64.3 & 61.8 & 68.90 & 7.8 \\
\hline 15 & 3 & 0.2 & 25 & 72.80 & 0.970 & 64.7 & 61.6 & 68.90 & 8.5 \\
\hline 16 & 3 & 0.2 & 25 & 73.90 & 1.100 & 65.7 & 62.6 & 69.99 & 8.6 \\
\hline 17 & 3 & 0.2 & 25 & 72.06 & 1.100 & 65.8 & 64.7 & 70.10 & 8.3 \\
\hline
\end{tabular}

TABlE 5: Regression coefficients for different antioxidant potential as responses.

\begin{tabular}{|c|c|c|c|c|c|c|}
\hline Term & DPPH Assay & Reducing power & $\begin{array}{c}\mathrm{Fe}^{2+} \text { scavenging } \\
\text { activity }\end{array}$ & FRAP assay & $\begin{array}{c}\text { NO scavenging } \\
\text { activity }\end{array}$ & ТPC \\
\hline Constant & -13.71 & $-1.483^{* *}$ & $-7.73^{*}$ & -1.38 & -1.57 & $-21.30^{* * *}$ \\
\hline Sucrose & $24.75^{* * *}$ & $0.504^{* *}$ & $21.60^{* *}$ & $18.06^{* * *}$ & $21.30^{* *}$ & $6.87^{* * *}$ \\
\hline $\mathrm{NaNO}_{3}$ & $142.02^{*}$ & $3.966^{* *}$ & $104.91^{*}$ & $101.89^{*}$ & $114.35^{*}$ & $40.84^{* *}$ \\
\hline Temperature & $2.00^{*}$ & $0.080^{* *}$ & $1.75^{*}$ & $1.51^{*}$ & $1.48^{*}$ & $1.00^{* *}$ \\
\hline Sucrose $\times$ sucrose & $-2.74^{* * *}$ & $-0.050^{* *}$ & $-2.45^{* *}$ & $-1.92 * * *$ & -2.57 & $-0.64^{* * *}$ \\
\hline $\mathrm{NaNO}_{3} \times \mathrm{NaNO}_{3}$ & 19.62 & 0.989 & 46.89 & -8.89 & 110.38 & $21.22 *$ \\
\hline $\begin{array}{l}\text { Temperature } \times \\
\text { temperature }\end{array}$ & $-0.03^{*}$ & -0.001 & $-0.02^{*}$ & $-0.02 *$ & -0.02 & $-0.01^{*}$ \\
\hline Sucrose $\times \mathrm{NaNO}_{3}$ & $-47.50^{* * *}$ & $-1.450^{* * *}$ & $-38.58^{* * *}$ & $-38.17^{* * *}$ & $-40.92^{* * *}$ & $-11.50^{* * *}$ \\
\hline Sucrose $\times$ temperature & 0.07 & $0.005^{*}$ & 0.04 & $0.05^{*}$ & $0.11^{*}$ & -0.02 \\
\hline $\mathrm{NaNO}_{3} \times$ temperature & -0.49 & -0.010 & -0.60 & 0.15 & $-1.67^{*}$ & $-0.92^{* *}$ \\
\hline$R^{2}$ & 90.7 & 94.1 & 86.8 & 92.1 & 87.6 & 94.8 \\
\hline
\end{tabular}

${ }^{*} P \leq 0.5 ;{ }^{* *} P \leq 0.05 ;{ }^{* *} P \leq 0.005$.

3.3. Toxicity Tests. The cell-free fungal extracts, when studied for Ames test, showed no mutagenic activity as no bacterial colony was observed on agar plates containing fungal extracts, while more that 1000 colonies were observed on positive control (sodium azide) containing plate. Similarly, results obtained from MTT assay revealed that the cellfree extracts were noncytotoxic and showed much higher absorbance (0.762) as compared to positive control (0.101).

3.4. Correlation between Antioxidant Activity and TPC. The results obtained indicate Penicillium granulatum to be a potent antioxidant producer having broad spectrum against various free radicals. To measure the total antioxidant potential using a single assay procedure seems to be unrealistic, yet there are numerous published methods claiming to measure total antioxidant activity in vitro [28]. Thus, to validate the reliability of different methods, the correlation between the different assay procedures is necessary. Previous studies have shown the linear correlation between total phenolic content and antioxidant activity [13] in this study too, total phenolic content of Penicillium granulatum correlated well with the antioxidant activity. The better production of phenolics under optimized conditions also resulted in enhanced antioxidant activity. The extract obtained from Penicillium granulatum showed good activity against DPPH 


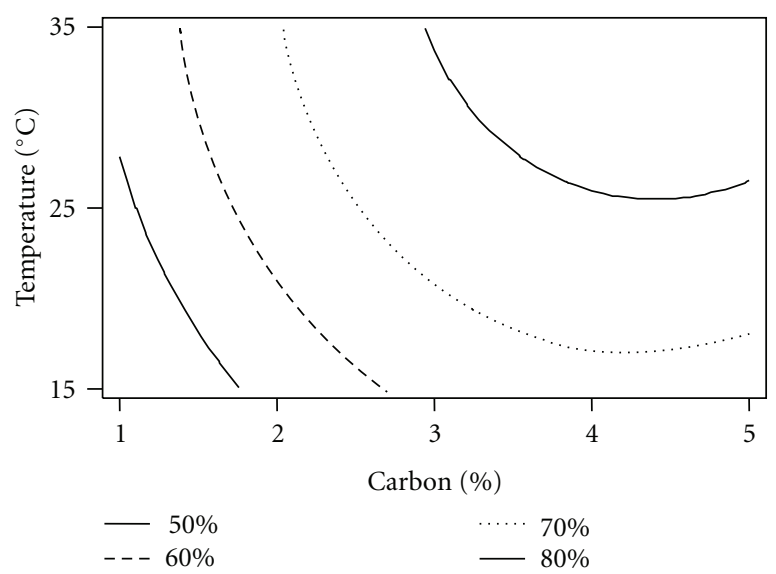

(a)

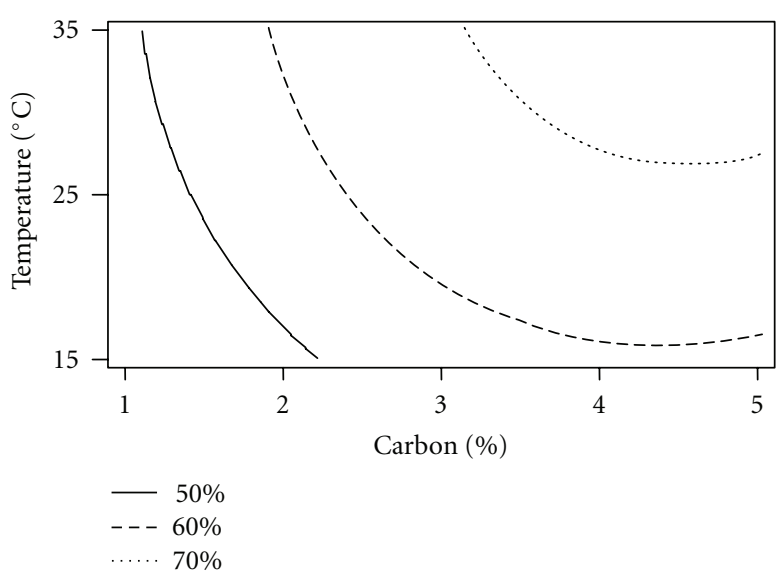

(c)

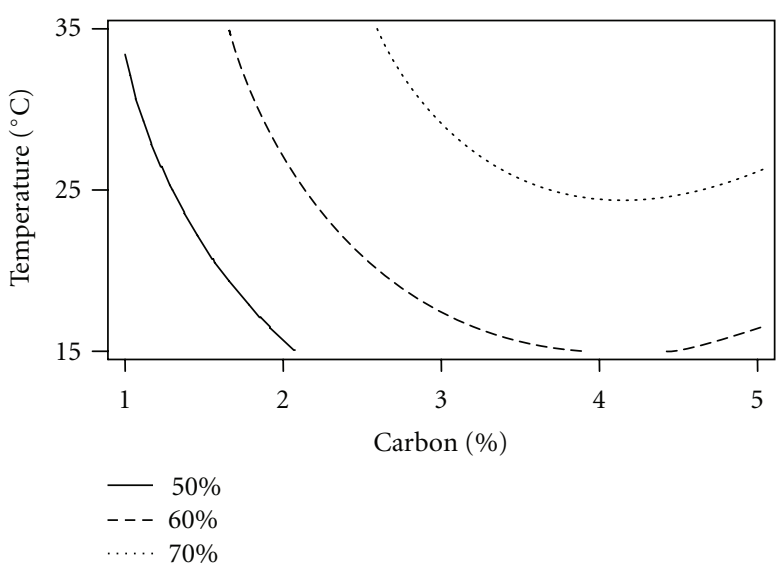

(e)

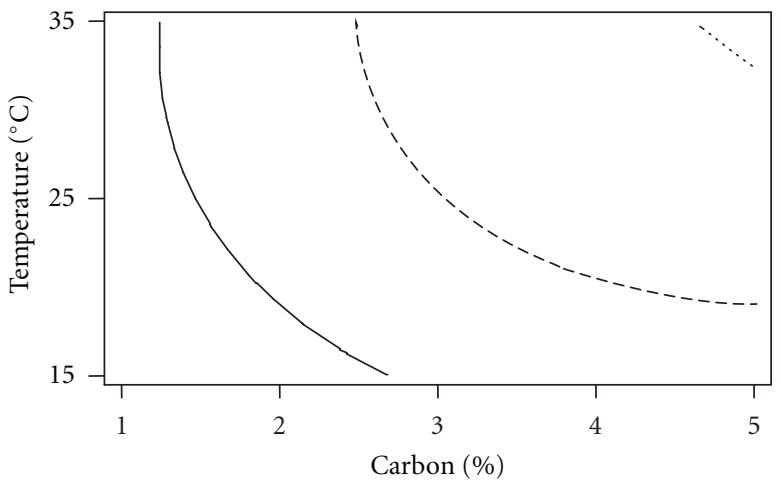

$-0.6$

$\begin{array}{ll}--- & 1.1\end{array}$

-.... 1.6

(b)

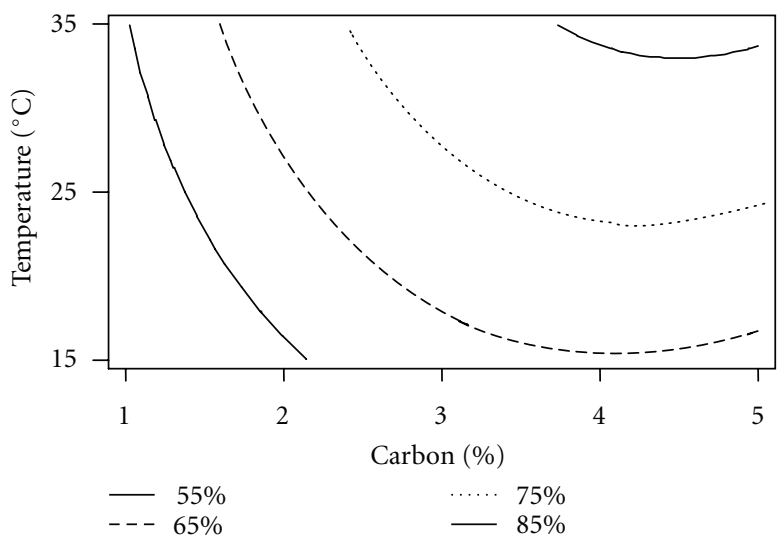

(d)

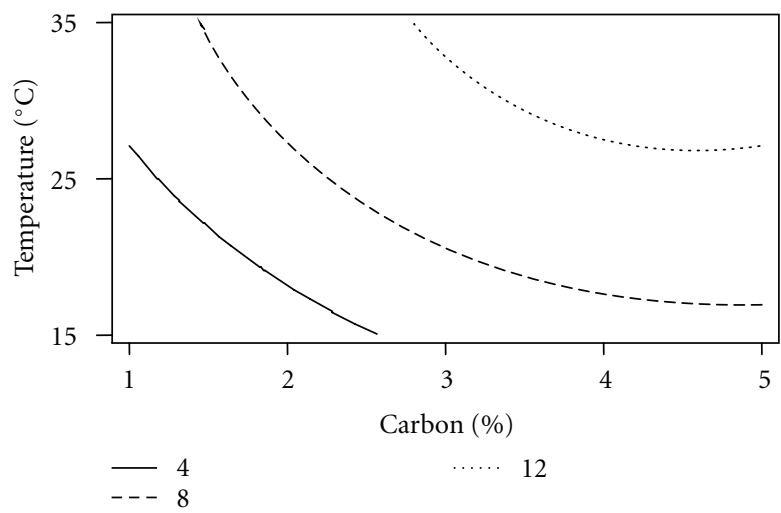

(f)

FIGURE 1: (a-f) Contour plot showing effect of different variables on antioxidant potential (hold value: $0.05 \%$ of sodium nitrate). (a) DPPH assay (\% activity); (b) reducing power (absorbance); (c) FRAP assay (\% activity); (d) nitric oxide ion scavenging activity (\% activity); (e) ferrous ion scavenging activity (\% activity); (f) total phenolic content $(\mathrm{mg} / \mathrm{ml})$.

radical by neutralizing the free radical character of purple color DPPH, either by transfer of electron or hydrogen atom, to yellow-colored diamagnetic molecule revealing hydrogen donating property of phenolic compounds present in the extract which can be supported by the positive correlation $(r=0.835)$ between the results of DPPH assay and TPC [29]. Similarly, positive correlation $(r=0.852)$ was found between reducing power assay and TPC. Reducing power assay proves the potential of the phenolic compounds in the extracts to act as reductones that inhibit lipid peroxidation by donating 
a hydrogen atom thereby terminating the free radical chain reaction. Moreover, this reducing potential may be due to the di or monohydroxy substitution in the aromatic rings that possess potent hydrogen-donating ability [12]. Results of FRAP assay are also positively correlated $(r=0.845)$ with TPC, and good activity of the fungal extract for FRAP assay denotes its reducing potential. Generally the reducing properties are associated to the breaking of free radical chain by donating a hydrogen atom [14]. The extracts also showed appreciable chelating activity of metals, as the transition metals such as ferrous ion can stimulate lipid peroxidation by generating hydroxyl radicals through Fenton reaction. The chelating activity for ferrous ion was assayed by the inhibition of formation of red-colored ferrozine and ferrous complex. There was positive correlation $(r=0.830)$ between chelating activity and TPC [12]. As evident from studies, the extracts are able to scavenge nitric oxide ion, and correlation between TPC was found to be positive $(r=0.826)$. $\mathrm{NO}^{\bullet}$ is an effective reactive radical that acts as an important oxidative biological signaling molecule in a large variety of diverse physiological processes, including neurotransmission, blood pressure regulation, defense mechanisms, smooth muscle relaxation and immune regulation. Overproduction of reactive nitrogen species is called nitrosative stress. Nitrosative stress may lead to nitrosylation reactions that can alter the structure of proteins and so inhibit their normal function and act as a potent-oxidizing agent that can cause DNA fragmentation and lipid peroxidation [30].

Most of the literature available is on antioxidant activity of plants and mushrooms though some of the fungi are known to produce antioxidant activity. To the best of our knowledge apparently this is the first systematic report on antioxidant activity of Penicillium granulatum demonstrated by different assay procedures and its optimization by statistical methods. These results are comparable with the antioxidant activity of various other fungi, Aspergillus candidus, Chaetomium sp., Cladosporium sp., Colletotrichum gloeosporioides [31] and many mushrooms such as Lentinus edodes, Volvariella volvacea [32] and many medicinal plants like Amaranthus paniculatus, Aerva lanata, Coccinia indica, and Coriandrum sativum [33].

\section{Conclusions}

The study thus suggests that not only mushrooms and plants but some other fungi may also be a good source of antioxidant compounds, and Penicillium granulatum is one such potential candidate offering a better scope for production and easier downstreaming of such bioactive compounds. These findings will facilitate the further studies to gain better understanding of production of bioactive metabolites in fungi, which will be helpful in their biotechnological mass production in near future.

\section{Abbreviations}

ANOVA: Analysis of variance

DPPH: 1,1-diphenyl-2-picryl hydrazyl

FC: $\quad$ Folin-Ciocalteau
FRAP: ferric reducing antioxidant power

GAE: Gallic acid equivalent

RSM: Response surface methodology

TPC: Total phenolic content.

\section{Acknowledgments}

Priyanka Chandra is thankful to University Grant Commission for Rajiv Gandhi National Fellowship vide no. F.42 (SC)/2008 (SA-III).

\section{References}

[1] N. Gursoy, C. Sarikurkcu, M. Cengiz, and M. H. Solak, "Antioxidant activities, metal contents, total phenolics and flavonoids of seven Morchella species," Food and Chemical Toxicology, vol. 47, no. 9, pp. 2381-2388, 2009.

[2] A. L. Demain, "Pharmaceutically active secondary metabolites of microorganisms," Applied Microbiology and Biotechnology, vol. 52, no. 4, pp. 455-463, 1999.

[3] A. Rančić, M. Soković, A. Karioti, J. Vukojević, and H. Skaltsa, "Isolation and structural elucidation of two secondary metabolites from the filamentous fungus Penicillium ochrochloron with antimicrobial activity," Environmental Toxicology and Pharmacology, vol. 22, no. 1, pp. 80-84, 2006.

[4] C. H. Chen, C. Y. Shaw, C. C. Chen, and Y. C. Tsai, "2,3,4-Trimethyl-5,7-dihydroxy-2,3-dihydrobenzofuran, a novel antioxidant, from Penicillium citrinum F5," Journal of Natural Products, vol. 65, no. 5, pp. 740-741, 2002.

[5] W. Y. Huang, Y. Z. Cai, K. D. Hyde, H. Corke, and M. Sun, "Endophytic fungi from Nerium oleander L (Apocynaceae): main constituents and antioxidant activity," World Journal of Microbiology and Biotechnology, vol. 23, no. 9, pp. 1253-1263, 2007.

[6] E. M. Heider, J. K. Harper, D. M. Grant et al., "Exploring unusual antioxidant activity in a benzoic acid derivative: a proposed mechanism for citrinin," Tetrahedron, vol. 62, no. 6 , pp. 1199-1208, 2006.

[7] R. Yawadio Nsimba, H. Kikuzaki, and Y. Konishi, "Antioxidant activity of various extracts and fractions of Chenopodium quinoa and Amaranthus spp. seeds," Food Chemistry, vol. 106, no. 2, pp. 760-766, 2008.

[8] T. Jayakumar, P. A. Thomas, and P. Geraldine, "In-vitro antioxidant activities of an ethanolic extract of the oyster mushroom, Pleurotus ostreatus," Innovative Food Science and Emerging Technologies, vol. 10, no. 2, pp. 228-234, 2009.

[9] P. Katapodis, V. Christakopoulou, and P. Christakopoulos, "Optimization of xylanase production by Thermomyces lanuginosus in tomato seed meal using response surface methodology," World Journal of Microbiology and Biotechnology, vol. 22, no. 5, pp. 501-506, 2006.

[10] Q. L. Wu, T. Chen, Y. Gan, X. Chen, and X. M. Zhao, "Optimization of riboflavin production by recombinant Bacillus subtilis RH44 using statistical designs," Applied Microbiology and Biotechnology, vol. 76, no. 4, pp. 783-794, 2007.

[11] D. S. Arora and P. Chandra, "Assay of antioxidant potential of two Aspergillus isolates by different methods under various physio-chemical conditions," Brazilian Journal of Microbiology, vol. 41, no. 3, pp. 765-777, 2010.

[12] G. R. Zhao, Z. J. Xiang, T. X. Ye, Y. J. Yuan, and Z. X. Guo, "Antioxidant activities of Salvia miltiorrhiza and Panax notoginseng," Food Chemistry, vol. 99, no. 4, pp. 767-774, 2006. 
[13] L. W. Chang, W. J. Yen, S. C. Huang, and P. D. Duh, "Antioxidant activity of sesame coat," Food Chemistry, vol. 78, no. 3, pp. 347-354, 2002.

[14] A. Othman, A. Ismail, N. Abdul Ghani, and I. Adenan, "Antioxidant capacity and phenolic content of cocoa beans," Food Chemistry, vol. 100, no. 4, pp. 1523-1530, 2007.

[15] S. K. Ki, T. Yokozawa, Y. K. Hyun, and H. P. Jeong, "Study on the nitric oxide scavenging effects of ginseng and its compounds," Journal of Agricultural and Food Chemistry, vol. 54, no. 7, pp. 2558-2562, 2006.

[16] V. L. Singleton, R. Orthofer, and R. M. Lamuela-Raventós, "Analysis of total phenols and other oxidation substrates and antioxidants by means of folin-ciocalteu reagent," Methods in Enzymology, vol. 299, pp. 152-178, 1998.

[17] P. Chandra and D. S. Arora, "Antioxidant activity of fungi isolated from soil of different areas of Punjab, India," Journal of Applied and Natural Science, vol. 1, pp. 123-128, 2009.

[18] D. M. Maron and B. N. Ames, "Revised methods for the Salmonella mutagenicity test," Mutation Research, vol. 113, no. 3-4, pp. 173-215, 1983.

[19] G. Ciapetti, E. Cenni, L. Pratelli, and A. Pizzoferrato, "In vitro evaluation of cell/biomaterial interaction by MTT assay," Biomaterials, vol. 14, no. 5, pp. 359-364, 1993.

[20] S. A. Sayyad, B. P. Panda, S. Javed, and M. Ali, "Optimization of nutrient parameters for lovastatin production by Monascus purpureus MTCC 369 under submerged fermentation using response surface methodology," Applied Microbiology and Biotechnology, vol. 73, no. 5, pp. 1054-1058, 2007.

[21] J. A. Macedo, L. D. Sette, and H. H. Sato, "Optimization of medium composition for transglutaminase production by a Brazilian soil Streptomyces sp.", Electronic Journal of Biotechnology, vol. 10, no. 4, pp. 618-626, 2007.

[22] G. C. Yen and Y. C. Chang, "Medium optimization for the production of antioxidants from Aspergillus candidus," Journal of Food Protection, vol. 62, no. 6, pp. 657-661, 1999.

[23] R. N. Tandon and J. S. Grewal, "Effect of nitrogen nutrition on growth and sporulation of some pathogenic fungi," Proceedings of the Indian Academy of Sciences B, vol. 44, no. 2, pp. 61-67, 1956.

[24] L. Miao, T. F. N. Kwong, and P. Y. Qian, "Effect of culture conditions on mycelial growth, antibacterial activity, and metabolite profiles of the marine-derived fungus Arthrinium c.f. saccharicola," Applied Microbiology and Biotechnology, vol. 72, no. 5, pp. 1063-1073, 2006.

[25] R. H. Hassegawa, M. C. M. Kasuya, and M. C. D. Vanetti, "Growth and antibacterial activity of Lentinula edodes in liquid media supplemented with agricultural wastes," Electronic Journal of Biotechnology, vol. 8, no. 2, pp. 212-217, 2005.

[26] D. K. Gogoi, H. P. Deka Boruah, R. Saikia, and T. C. Bora, "Optimization of process parameters for improved production of bioactive metabolite by a novel endophytic fungus Fusarium sp. DF2 isolated from Taxus wallichiana of North East India," World Journal of Microbiology and Biotechnology, vol. 24, no. 1, pp. 79-87, 2008.

[27] S. Trupkin, L. Levin, F. Forchiassin, and A. Viale, "Optimization of a culture medium for ligninolytic enzyme production and synthetic dye decolourization using response surface methodology," Journal of Industrial Microbiology and Biotechnology, vol. 30, no. 12, pp. 682-690, 2003.

[28] B. Sultana, F. Anwar, and R. Przybylski, "Antioxidant activity of phenolic components present in barks of Azadirachta indica, Terminalia arjuna, Acacia nilotica, and Eugenia jambolana Lam. trees," Food Chemistry, vol. 104, no. 3, pp. 1106 1114, 2007.
[29] S. Bounatirou, S. Smiti, M. G. Miguel et al., "Chemical composition, antioxidant and antibacterial activities of the essential oils isolated from Tunisian Thymus capitatus Hoff. et Link.", Food Chemistry, vol. 105, no. 1, pp. 146-155, 2007.

[30] F. Abas, N. H. Lajis, D. A. Israf, S. Khozirah, and Y. U. Kalsom, "Antioxidant and nitric oxide inhibition activities of selected Malay traditional vegetables," Food Chemistry, vol. 95, no. 4, pp. 566-573, 2006.

[31] M. Femenía-Ríos, C. M. García-Pajón, R. Hernández-Galán, A. J. Macías-Sánchez, and I. G. Collado, "Synthesis and free radical scavenging activity of a novel metabolite from the fungus Colletotrichum gloeosporioides," Bioorganic and Medicinal Chemistry Letters, vol. 16, no. 22, pp. 5836-5839, 2006.

[32] L. M. Cheung and P. C. K. Cheung, "Mushroom extracts with antioxidant activity against lipid peroxidation," Food Chemistry, vol. 89, no. 3, pp. 403-409, 2005.

[33] S. S. Ali, N. Kasoju, A. Luthra et al., "Indian medicinal herbs as sources of antioxidants," Food Research International, vol. 41, no. 1, pp. 1-15, 2008. 

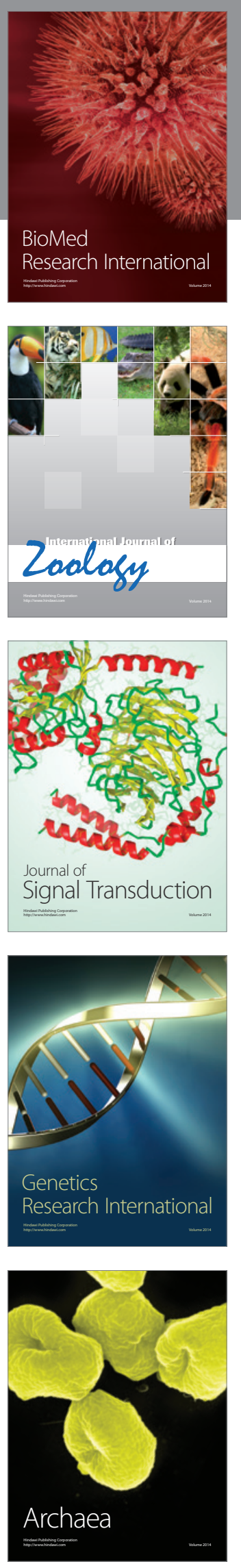
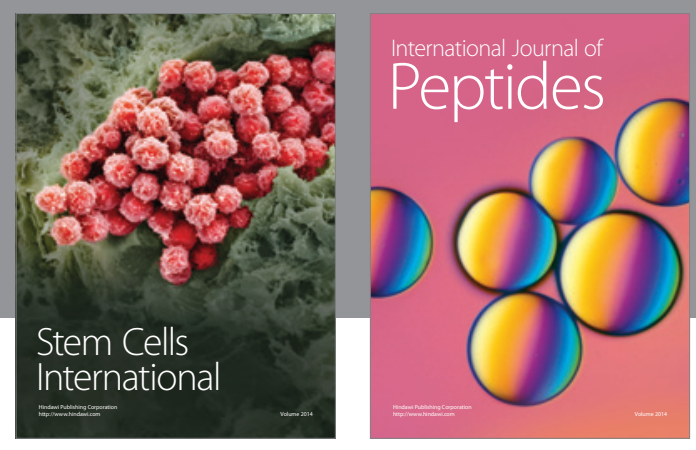

Submit your manuscripts at

http://www.hindawi.com
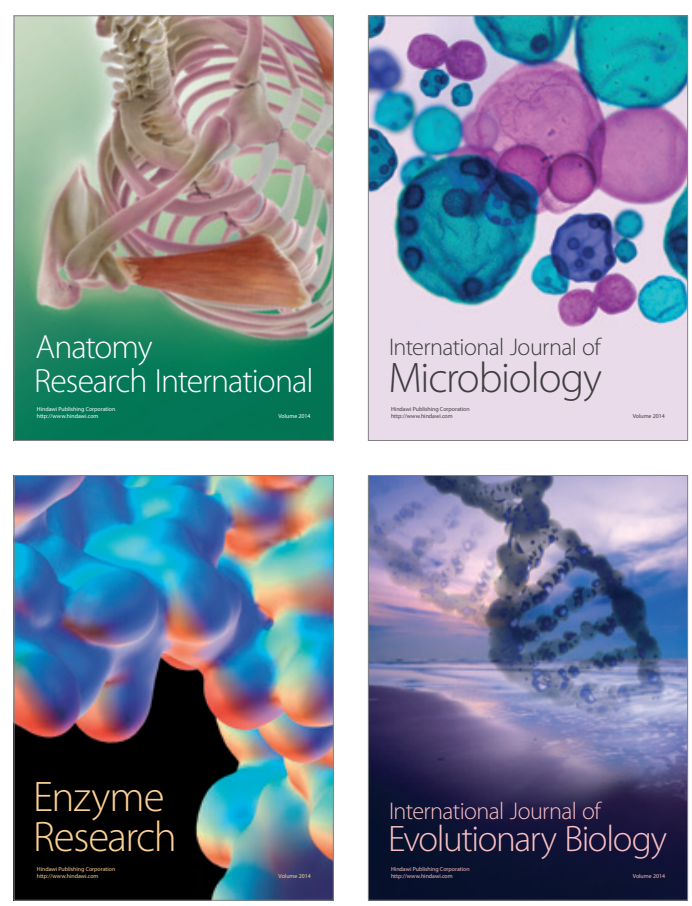
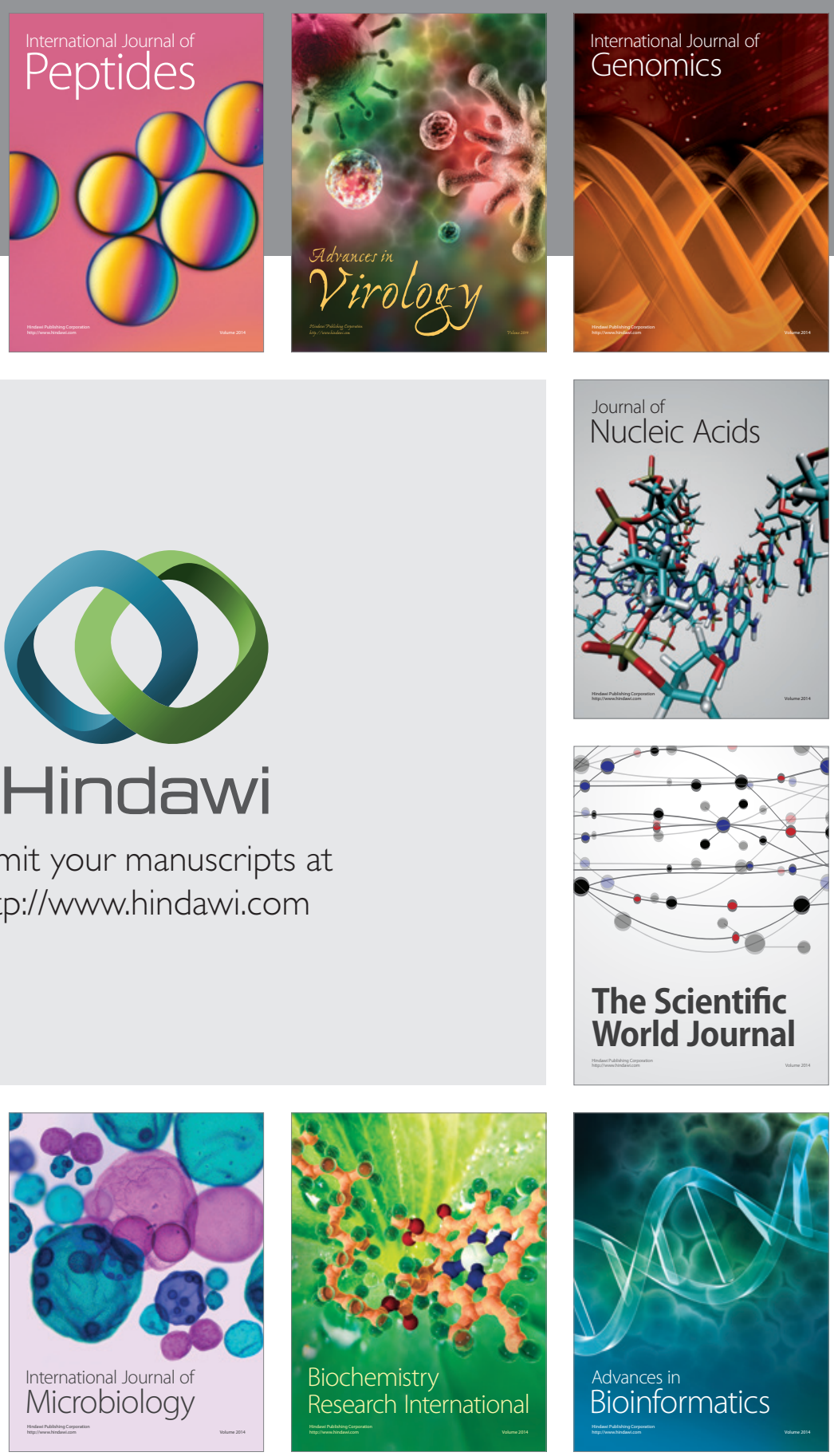

The Scientific World Journal
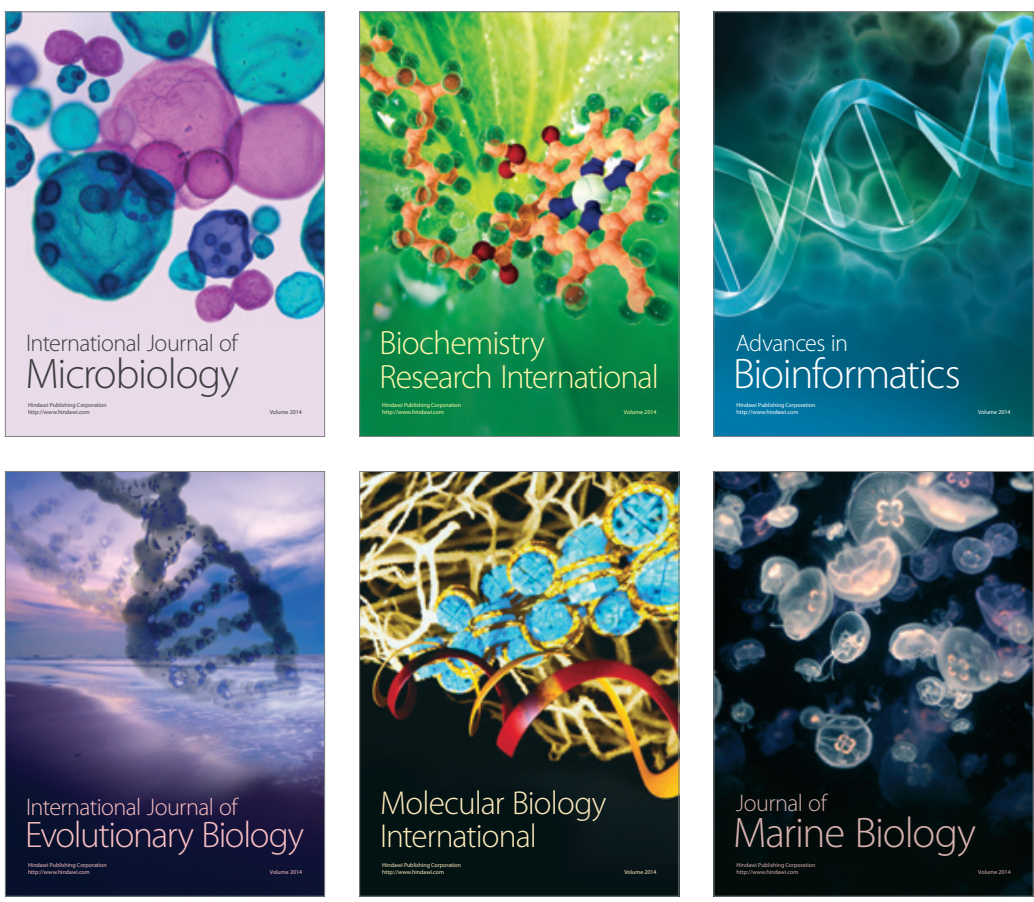